\title{
Electronic Structure of 2H-Tetraphenylporphyrin at Fe/Si (100) Interface
}

\author{
Chhagan Lal ${ }^{1,2,3}$ and I. P. Jain ${ }^{3}$ \\ ${ }^{1}$ Synchrotron S.c.p.A., SS-14 km, 163.5, in Area Science Park, Basovizza, 34149 Trieste, Italy \\ ${ }^{2}$ International Centre for Theoretical Physics, Strada Costiera 11, 34151 Trieste, Italy \\ ${ }^{3}$ Centre for Nonconventional Energy Resources, University of Rajasthan, Jaipur-04, India \\ Correspondence should be addressed to Chhagan Lal; clsaini52@gmail.com
}

Received 24 June 2013; Accepted 16 July 2013

Academic Editors: C. M. Chan and J. N. Latosinska

Copyright (c) 2013 C. Lal and I. P. Jain. This is an open access article distributed under the Creative Commons Attribution License, which permits unrestricted use, distribution, and reproduction in any medium, provided the original work is properly cited.

\begin{abstract}
Many recent studies have highlighted the possibility to tailor the physical and chemical properties of porphyrin at the molecular level to design novel catalysts, sensors and devices with applications in electronics, opto-electronics, and so forth. In the present work, we study the electronic properties of $2 \mathrm{H}$-Tetraphenylporphyrin (2H-TPP) on iron (Fe) and iron silicide $\left(\mathrm{Fe}_{3} \mathrm{Si}\right.$ ) onto $\mathrm{Si}(100)$ substrate using X-ray and Ultraviolet photoelectron spectroscopy (XPS \& UPS). The results revealed that the iron atom is coordinated by $\mathrm{TPP}$ molecules on $\mathrm{Fe} / \mathrm{Si}$ as well as on $\mathrm{Fe}_{3} \mathrm{Si} / \mathrm{Si}$. XPS results provide evidence of the iron coordination with TPP molecules. The UPS analysis evidenced the fine structure in the electronic spectra related to HOMO states below the Fermi level.
\end{abstract}

\section{Introduction}

The adsorption of functional molecules on solid substrates has become important in the field of nanoscience and, hence, to exploit the potential of bottom-up strategies the nanostructures are grown in a controlled way. It is known that the position and dimension of the molecular assemblies can be tuned and controlled with high precision down to the atomic level on metals [1-3] and semiconductors [4-7]. Developing technologically robust families of adsorbed assemblies on semiconductor surfaces is challenging, especially because the electronic skeleton of molecules is slightly altered after the adsorption $[8,9]$.

Organic/inorganic interfaces are intriguing and challenging because of the wide variety of phenomena they exhibit, and these interfaces have evolved as a potential alternative to conventional electronic devices. The flexibility afforded by organic molecular films in terms of modes of deposition, chemical functionalization, molecular mixing, and doping opens a number of routes to tailor the interface properties, which would not be possible with inorganic materials [10]. Porphyrins are a flexible class of molecules with a square symmetry planar core conformation (macrocycle) and two-dimensional conjugated $\pi$ electron delocalization [1113]. These organic molecules are one of the most studied systems because of their ability to absorb light, to interact with gases, and their involvement in many biological systems. However, they combine a structure-forming element the porphyrin framework with an active site of the porphyrin core.

The intrinsic functionality of porphyrins is given by their ability to bind 1st transition row metal atoms at the centre of the macrocycle to form a metalloporphyrin. Many of these molecules are commercially available or can be produced via metalation reactions in Ultra High Vacuum (UHV). The metalation reaction is, in many cases, energetically proved independently on the order of deposition, for example, adsorbed $2 \mathrm{H}$-TPP molecules react with metal atoms irrespective of which reactant is deposited first.

The commercially available Fe-porphyrins also have a $\mathrm{Cl}$ bonded to the iron to stabilize the highly reactive metal that can easily oxidize. The possibility to produce stable Feporphyrins with no $\mathrm{Cl}$ atoms and to characterize them in situ is an intriguing challenge because of their key role as main building blocks in important biological molecules as well as for magnetic systems and catalytic processes $[14,15]$. 
The formation of cobalt (II) and iron (II) tetraphenylporphyrins (MTPP's, $\mathrm{M}=\mathrm{Co}, \mathrm{Fe}$ ) from the direct reaction of the bare metal atoms (Co or $\mathrm{Fe}$ ) and adsorbed tetraphenylporphyrin (2H-TPP) molecules have been reported authors [16, 17]. The adsorbed porphyrin monolayer efficiently metallated in situ under clean UHV conditions by evaporation onto the metal atoms which increase the possibility to study metalloporphyrins using surface science techniques at low sample temperatures.

Pure Fe-tetraphenylporphyrin (Fe-TPP) was produced under UHV conditions by in situ metalation of free-base $2 \mathrm{H}-5,10,15,20$-tetraphenylporphyrin (2H-TPP) monolayers with Fe atoms deposited by an electron beam evaporator [17]. STM micrographs showed the appearance of intramolecular protrusions consequent to Fe evaporation and the evidence of the TPP metalation. Similar experiments have been performed for Co and Ce [18]. Moreover, photoemission studies, performed with laboratory X-ray sources, have demonstrated metalation by $\mathrm{Fe}, \mathrm{Zn}$, and $\mathrm{Co}$ of free-base porphyrins by collecting the $\mathrm{N}$ 1s core level signal together with the metal peak [19].

In the present work, the electronic structure of the interface between $2 \mathrm{H}$-Tetraphenylporphyrin (2H-TPP) and iron or iron silicide on $\mathrm{Si}(100)$ substrate is studied using X-ray Photoelectron Spectroscopy (XPS) and Ultraviolet Photoelectron Spectroscopy (UPS). The choice of these substrates is guided by the fact that the magnetic properties of the molecules are altered by the deposition on metal surfaces or metal on semiconductor, suggesting a possibility of engineering magnetic nanostructures for potential use in spintronics.

\section{Expermental Section}

Measurements were performed in the UHV chamber at a pressure of $<10^{-10}$ mbar in Micro- and Nanocarbon Lab, Elettra Synchrotron facility, Trieste, Italy. Sample preparation was made in situ evaporating 2H-TPP (99.95\%, Sigma Aldrich) by a resistively heated Tantalum (Ta) evaporator on magnetic layers at $\mathrm{Si}(100)$ substrate. Before the deposition of magnetic layers, Si (100)- $2 \times 1$ substrate surface was first reconstructed by removing the natural oxide by annealing at $\sim 1200 \mathrm{~K}$. $2 \times 1$ reconstruction of $\mathrm{Si}$ is confirmed by Low Energy Electron Diffraction (LEED). The absence of contaminants and ordering of the surface were checked by means of XPS, LEED, and UPS. Two different systems were prepared for the spectroscopy measurements in the following ways.

(a) Hundreds of monolayer of Fe atoms were deposited using homemade E-beam evaporator having, Filament power $=4.7 \mathrm{Amp} \times 1.5$ Volt, H.V. $=1250$ Volt, $I_{\text {emission }}=13$ Milliamps for 20 minutes on Si (100) and then evaporated multilayer of $2 \mathrm{H}$-TPP molecules. The specimen was heated at $550 \mathrm{~K}$ for 5 minutes to adsorb the Fe atoms in the TPP macrocycle to form a monolayer of metalloporphyrin molecules.

(b) In another type of sample, prior to deposition of molecules, the Fe/Si system was annealed at $660 \mathrm{~K}$ for 45 minutes in UHV to form iron silicide $\left(\mathrm{Fe}_{3} \mathrm{Si}\right)$.
Thereafter, multilayer of 2H-TPP molecules were deposited on iron silicide onto $\mathrm{Si}$ substrate which was annealed at $550 \mathrm{~K}$ to see interaction of the iron with TPP macrocycle and yielded metalloporphyrin monolayer at the system.

All experiments were performed with a commercial X-ray photoelectron spectrometer (VG-ESCALAB-II) equipped with an $\mathrm{Al} \mathrm{K} \alpha \mathrm{X}$-ray source $(1486.6 \mathrm{eV})$ and a hemispherical energy analyzer with base pressure in this UHV system is below $1 \times 10^{-10} \mathrm{mbar}$. In addition to the XPS spectrometer, the system is equipped with a differentially pumped gas discharge lamp for UV photoelectron spectroscopy (UPS), LEED optics (SPECS ErLEED-1000A) and evaporators.

\section{Results and Disscusion}

The growth of iron and the formation of iron silicide on Si (100) have been followed by XPS and UPS, as shown in Figure 1. The Fe overlayer thickness can be estimated by the quantitative evaluation of the $\mathrm{Si} 2 \mathrm{p}$ core level peaks area attenuation ( 904). In Figure 1(a), we show a comparison between the wide energy spectrum including Si 2 s, Si $2 p$, and $\mathrm{Fe} 3 \mathrm{p}$ core level peaks in the case of clean $\mathrm{Si}, \mathrm{Fe} / \mathrm{Si}$ measured at $\mathrm{RT}$ and after annealing at $660 \mathrm{~K}$. It is worth noting that Fe $3 \mathrm{p}$ rigidly shifts of $1.3 \mathrm{eV}$ towards higher $\mathrm{BE}$ (inset of Figure 1(a)), while Si 2 p \& 2s are not shifted after annealing at $660 \mathrm{~K}$. Figure 1(b) shows the Fe 2p core level of Fe/Si system at room temperature (RT) and $660 \mathrm{~K}$. The binding energy of Fe $2 \mathrm{p}_{3 / 2}$ is located at $707 \mathrm{eV}$ corresponding well to the metallic iron $\mathrm{Fe}$ $2 \mathrm{p}_{3 / 2}$ peak for the RT grown sample. Asymmetry shown by $\mathrm{Fe}$ $2 p$ core-level lines and it arises due to an increase in the state density at the Fermi level [20]. The asymmetric line shape indicates the formation of metallic silicides namely $\mathrm{Fe}_{3} \mathrm{Si}$ and $\mathcal{E}$-FeSi. The value of the binding energy for a given core level measured by XPS depends on its chemical environment. The XPS spectra show a change in intensity of the silicon peak and the chemical shift occurred for the Fe 3p. The shift in energy towards higher binding energy is observed $0.11 \mathrm{eV}$ for $\mathrm{Fe} 2 \mathrm{p}_{3 / 2}$ peak. Moreover, the value of the full width at half maxima is reduced compared to the RT case. These shifts and the narrowed line-width of the $\mathrm{Fe} 2 \mathrm{p}_{3 / 2}$ indicate the formation of the iron silicide $\left(\mathrm{Fe}_{3} \mathrm{Si}\right)$ through the reaction between silicon and iron at $660 \mathrm{~K}$. In fact, the value of $0.11 \mathrm{eV}$ is in good agreement with previous reports [21]. However, the silicon $2 \mathrm{p}$ and $2 \mathrm{~s}$ peaks do not show any significant shift after the iron silicide phase formation, disagreeing with the previous reported results $[22,23]$. Figure $1(\mathrm{c})$ shows the valence band spectrum of $\mathrm{Si}$ and $\mathrm{Fe} / \mathrm{Si}$ system at RT and $660 \mathrm{~K}$. Clean $\mathrm{Si}$ shows the well-known surface state band at $0.85 \mathrm{eV}$ below the Fermi level and the bulk derived state at $2.8 \mathrm{eV}$. The Fe/Si spectrum shows a high density of states (DOS) at Fermi level and d-derived peaks at $1 \mathrm{eV}$, in agreement with spectra for bulk Fe [24]. The new features near the Fermi level edge arising in the case of iron silicide, indicate an overlap between the Fe and the Si bands.

Low energy electron diffraction (LEED) measurements are also carried out to confirm the iron silicide $\left(\mathrm{Fe}_{3} \mathrm{Si}\right)$ formation and it shows $1 \times 1$ patterns. The LEED patterns are 


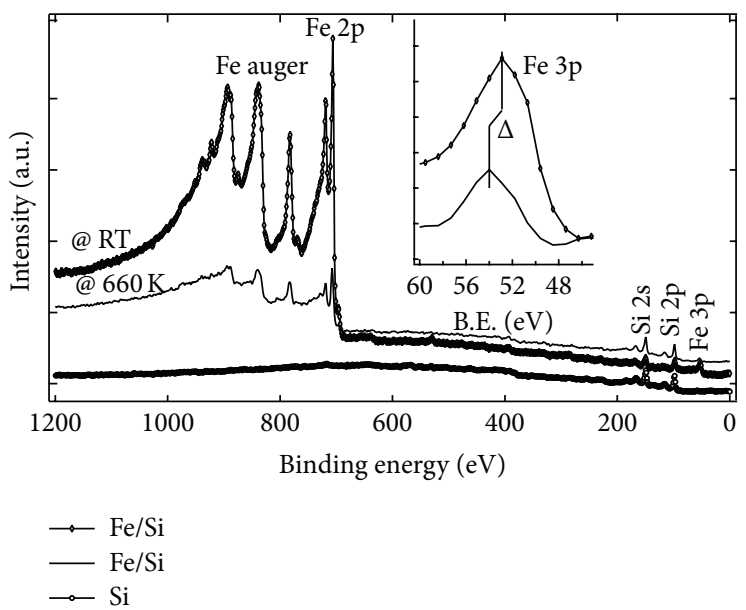

(a)

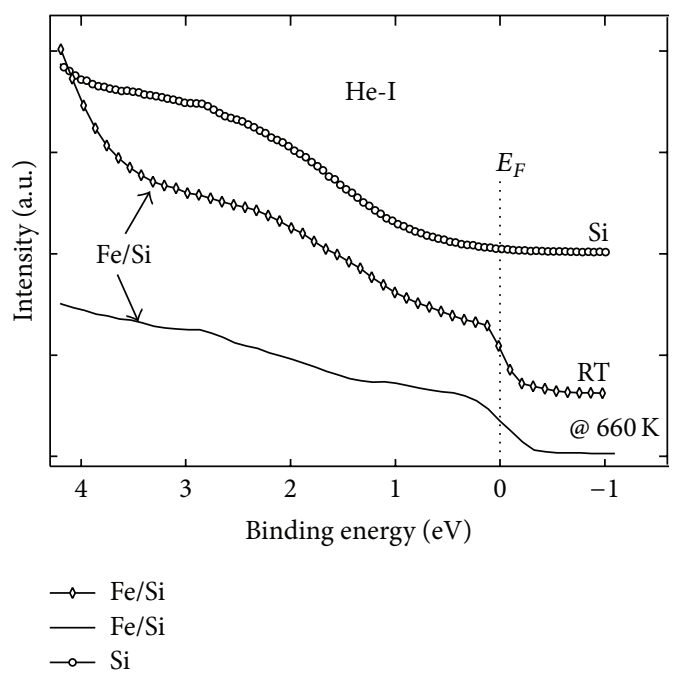

(c)

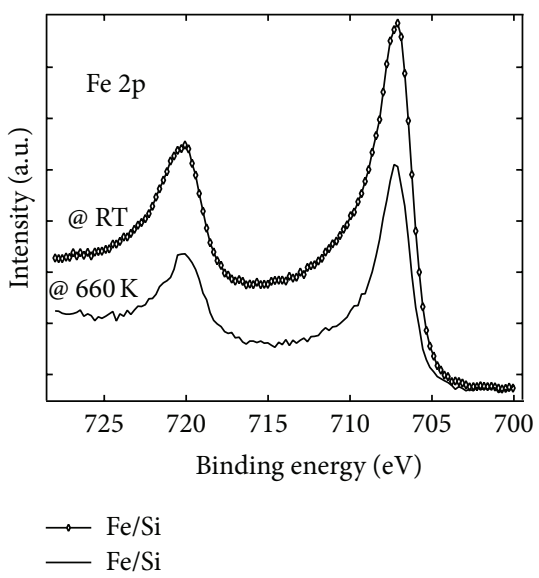

(b)

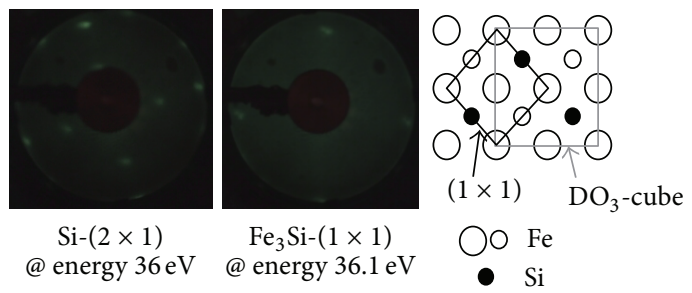

(d) LEED View of $\mathrm{Si}, \mathrm{DO}_{3}$ phase of $\mathrm{Fe}_{3} \mathrm{Si}$ and atomics model

FIGURE 1: (a) Survey spectra of clean Si and Fe deposited on Si at RT \& $660 \mathrm{~K}$. Inset show the change in Fe 3p, (b) Core level spectra of Fe $2 \mathrm{p}$, and (c) UPS spectra of clean $\mathrm{Si}$ and Fe deposited on $\mathrm{Si}$ at RT \& $660 \mathrm{~K}$, (d) LEED pattern of $\mathrm{Si}, \mathrm{Fe}_{3} \mathrm{Si}$ and atomic model for the unit cell notation.

shown in Figure 1(d) for the $\mathrm{DO}_{3}$ phase formed on $\mathrm{Si}$ and matched with the theoretical predicated atomic model. The crystal structure $\left(\mathrm{DO}_{3}\right)$ of $\mathrm{Fe}_{3} \mathrm{Si}$ phase on Si substrate can be described by a cubic unit cell consisting of four bcc and four $\mathrm{CsCl}$ type cubes [25]. Different from a pure Fe bcc lattice, the centered iron atom in every other cube is substituted by silicon. As a result, the nominal $1 \times 1$ surface structure is observed for $\mathrm{Fe}_{3} \mathrm{Si}$ phase because the unit cell of the $\mathrm{DO}_{3}$ structure of $\mathrm{Fe}_{3} \mathrm{Si}$ made up of bcc- and CsCl-type subcubes. Random occupancies of sites B (for $\mathrm{Fe}$ ) and C (for $\mathrm{Si}$ ), or all three sites, lead to $\mathrm{CsCl}$ or bcc, respectively. The phase diagrams [26] also support the formation of $\mathrm{Fe}_{3} \mathrm{Si}$ on $\mathrm{Si}$ at $660 \mathrm{~K}$.

The spectroscopic investigations were undertaken on $\sim 10 \mathrm{ML}$ of $2 \mathrm{H}$-TPP on iron $(\mathrm{Fe})$ and iron silicide $\left(\mathrm{Fe}_{3} \mathrm{Si}\right)$ onto $\mathrm{Si}$ (100). Chemical analysis of the reaction was carried out using XPS to studying metalation with $\mathrm{Fe}$, by monitoring the core level of nitrogen (N 1s) and carbon (C 1s).
X-ray photoemission spectra provide the straightforward way to monitor the progress of the metalation of $2 \mathrm{H}-\mathrm{TPP}$, to follow the changes in the $\mathrm{N}$ 1s core level signal. In details the $\mathrm{N}$ 1s spectrum of $2 \mathrm{H}$-TPP has two easily resolved component of the two $\mathrm{N}$ species (iminic and pyrrolic) and as the reaction proceed, just one peak is expected for the metallated porphyrin (metalloporphyrin), because in the final state of metalloporphyrin complex the four nitrogen atoms are chemically equivalent. We show the $\mathrm{N}$ 1s core level XPS of TPP multilayer and formation of metalloporphyrin (Fe-TPP) on $\mathrm{Fe}$ and $\mathrm{Fe}_{3} \mathrm{Si}$ onto $\mathrm{Si}$ in Figure 2. In 2H-TPP multilayer, the $\mathrm{N}$ 1s (Figures 2(a) and 2(c)) has two well resolved peaks: the one at higher Binding Energy (BE) is assigned to the two pyrrolic $\mathrm{N}$ atoms (-NH-), while the lower $\mathrm{BE}$ peak corresponds to the two iminic ones $(-\mathrm{N}=)$ [27]. These two peaks were shown with their fwhm by fitting the raw data and obtained results are reported in Table 1, which point out that the pyrrolic peak is broader than the iminic and 
TABLE 1: N 1s components-multilayer of TPP molecules on Fe and $\mathrm{Fe}_{3} \mathrm{Si}$ onto $\mathrm{Si}$.

\begin{tabular}{lccc}
\hline \multirow{2}{*}{ Sample at RT } & \multicolumn{3}{c}{ Normalized peaks } \\
& in $(\mathrm{eV})$ & $-\mathrm{N}=$ & $-\mathrm{NH}-$ \\
\hline \multirow{2}{*}{$2 \mathrm{HTPP} / \mathrm{Fe} / \mathrm{Si}$} & $\mathrm{BE}$ & 398.16 & 400.25 \\
& $\mathrm{fwhm}$ & 0.8929 & 1.1671 \\
$2 \mathrm{HTPP} / \mathrm{Fe}_{3} \mathrm{Si} / \mathrm{Si}$ & $\mathrm{BE}$ & 398.15 & 400.26 \\
& $\mathrm{fwhm}$ & 0.8682 & 1.5612 \\
\hline
\end{tabular}

TABLE 2: N 1s components-monolayer of Fe-TPP complex formation on $\mathrm{Fe}$ and $\mathrm{Fe}_{3} \mathrm{Si}$ onto Si.

\begin{tabular}{lcccc}
\hline \multirow{2}{*}{ Sample at $550 \mathrm{~K}$} & \multicolumn{4}{c}{ Normalized peaks } \\
& in $(\mathrm{eV})$ & $-\mathrm{N}=$ & $-\mathrm{NH}-$ & $\mathrm{N}-\mathrm{Fe}$ \\
\hline \multirow{2}{*}{$2 \mathrm{HTPP} / \mathrm{Fe} / \mathrm{Si}$} & $\mathrm{BE}$ & 397.98 & 400.07 & 398.9 \\
& fwhm & 0.8929 & 1.1671 & 0.7142 \\
$2 \mathrm{HTPP} / \mathrm{Fe}_{3} \mathrm{Si} / \mathrm{Si}$ & $\mathrm{BE}$ & 398.09 & 400.20 & 399.31 \\
& fwhm & 0.8682 & 1.5612 & 0.8886 \\
\hline
\end{tabular}

are in good agreement with reported results $[16,19]$. However, it is difficult to ascertain that the two kinds of $\mathrm{N} 1 \mathrm{~s}$ atoms with such fwhm difference have a different core-hole lifetime that should be related to very distinct de-excitation mechanisms [28].

Metalation of porphyrin multilayer was demonstrated by the formation of Fe-TPP monolayer upon annealing at $550 \mathrm{~K}$ of $2 \mathrm{H}$-TPP multilayer on $\mathrm{Fe}$ and $\mathrm{Fe}_{3} \mathrm{Si}$ onto $\mathrm{Si}$. The efficiency of the reaction is lower than for monolayer. In fact the metalation competes with the formation of $\mathrm{Fe}$ clusters in the multilayer [29]. The monolayer formation of metalloporphyrin (Fe-TPP) in both cases are shown in Figures 2(b) and 2(d), respectively. The simplest possible approach to interpret the signal of $\mathrm{N} 1 \mathrm{~s}$ assumes that it arises from a mixture of the product Fe-TPP and unreacted TPP. Accordingly, we attempted a peak synthesis with the fitted signals of TPP and Fe-TPP. To obtain better agreement it was necessary to introduce one additional peak, represented by the middle peak (sky blue) with two nitrogen (iminic and pyrrolic) peaks (while separation in $\mathrm{BE}$, fwhm, and ratio of intensity were held constant for fitting the peaks) in the $\mathrm{N}$ 1 s spectra of metalloporphyrin. While the position was not held constant during the fitting for better resolution and the best fit results were reported in Table 2. The shifts in peak position of iminic and pyrrolic $\mathrm{N}$ atoms have been observed toward lower binding energies and represent the sign of the formation of Fe-TPP monolayer. The new component peak here represents the coordination of iron $(\mathrm{Fe})$ and nitrogen $(\mathrm{N})$ of TPP macrocycle. The variation in BE of the coordination peak is due to different interaction of $\mathrm{Fe}$ on iron and iron silicide.

The signal of pyrrolic $\mathrm{N}$ decreased upon heat treatment of the specimens at $550 \mathrm{~K}$ and results indicate a fraction of $2 \mathrm{H}$-TPP molecules had undergone the metalation reaction to Fe-TPP. The $\mathrm{N}$ 1s core level of Fe-TPP monolayer have three component of iminic, pyrrolic and N-Fe, while Xiao et al. reported [30] that the iminic (pyrrolic) peak completely vanishes above $450 \mathrm{~K}$ in subone monolayer systems.

Here, the observed results are related to partial thermal desorption of the molecule: the $\mathrm{N}$ 1s and $\mathrm{C}$ 1s (Figure 3) core level intensities show that the total coverage is changed during heating, assuming that the molecules desorbed and monolayer of metalloporphyrin is yielded at the surface. The temperature dependent $C$ 1s core level result has expect to reflect the information about the distance between the molecules and iron atoms on $\mathrm{Si}(100)$ substrate as well as the tilting of the molecules. The shift of $0.22 \mathrm{eV}$ in $\mathrm{BE}$ of $\mathrm{C}$ 1 s core level towards lower binding energy is observed and show the molecular-surface distance is decreased as a result of annealing at $550 \mathrm{~K} \mathrm{[30].}$

It is challenging both theoretically and experimentally to study the valance bands of large conjugated molecules of closely spaced molecular states. Experimentally, energy positions of molecular orbitals in organic layers can be studied by Ultraviolet Photoemission Spectroscopy (UPS) or by Scanning Tunneling Spectroscopy (STS) [31, 32]. UPS has the advantage that accessible binding energies are not limited to a few electron volts from the Fermi level as STS. Thus, UPS is the technique of choice for studying the highest energy molecular orbitals of the metal porphyrin complexes (metalloporphyrin), where He-I $(21.22 \mathrm{eV})$ was used to measure the valence band of $2 \mathrm{H}$-TPP on iron $(\mathrm{Fe})$ and iron silicide $\left(\mathrm{Fe}_{3} \mathrm{Si}\right)$ onto $\mathrm{Si}$. The metal coordination with TPP macrocycle has been studied additionally by UPS. Figure 4 shows the Valence Band (VB) raw data of TPP multilayer and monolayer of metalloporphyrin (Fe-TPP). The multilayer valence band results show that the Fe-TPP bonds are extremely stable and strong.

The occupied molecular orbital's (HOMO) of $2 \mathrm{H}-\mathrm{TPP}$ multilayer on iron and iron silicide onto $\mathrm{Si}$ are shown in Figure 4 (a). The peaks at BE of $-1.765,-3.965,-6.495$, and $-8.585 \mathrm{eV}$ were represented by $\mathrm{A}, \mathrm{B}, \mathrm{C}$, and $\mathrm{D}$, respectively, and corresponding to HOMO states below the Fermi level. The monolayer of Fe-TPP is shown in Figures 4(b) and 4(c). The change in surface band of of monolayer is found at low $\mathrm{BE}$ than the multilayer, on comparison of $\mathrm{VB}$ spectra. The major changes are below $5 \mathrm{eV}$ of $\mathrm{BE}$ and in particular, the growth of states near the Fermi level show an apparent metallic behavior. The growth in intensity of DOS spectra near the Fermi level is due to the d orbitals of the iron upon annealing at $550 \mathrm{~K}$ and evidenced the TPP macrocycle binds the Fe.

To further analysis of the valence band raw data, we show a typical valence band spectra in Figure 4(d), where the reported valence band has been obtained by subtracting the spectrum of $2 \mathrm{H}$-TPP multilayer from the valence band of Fe-TPP monolayer. This procedure is obviously quite rough, but helps us to highlight some important features. The $\mathrm{Fe}$ metalation influences the states near the Fermi level $(0-2 \mathrm{eV})$, and show that behave of the layer tend to metallic. Therefore, the intensity at the Fermi level seen in monolayer valence band is due to metallization. The full UPS spectra of $\mathrm{Fe}_{3} \mathrm{Si}$ on $\mathrm{Si}$ have been shown in Figure 4(e). From the comparison between the spectra of (d) and (e) of Figure 4, we conclude that the charge injection from the substrate is confined and 


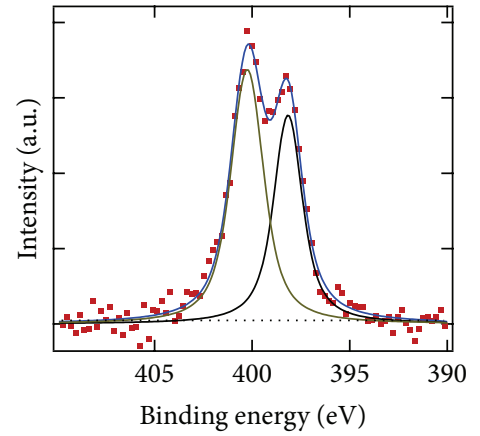

(a)

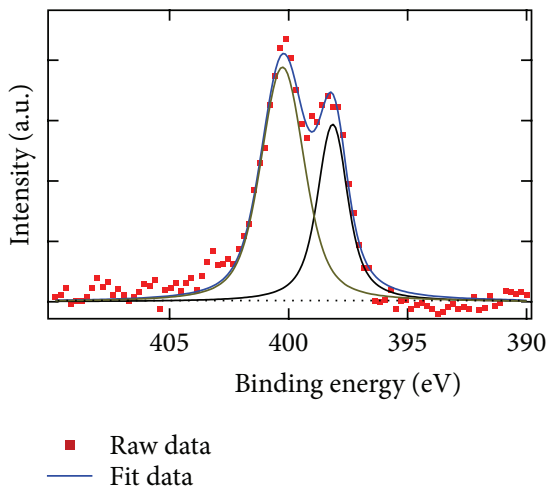

(c)

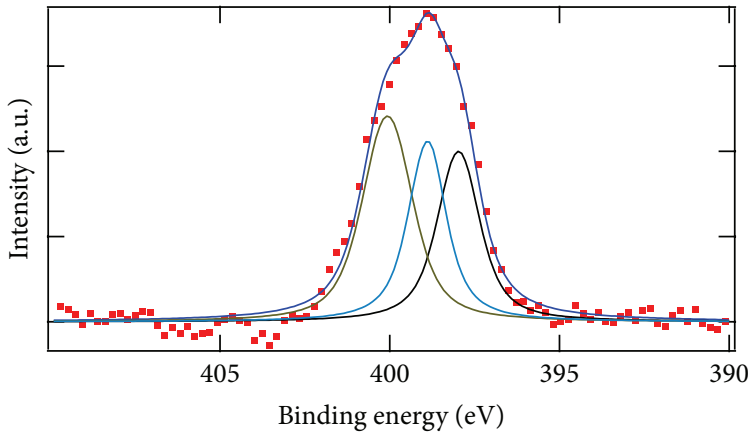

(b)

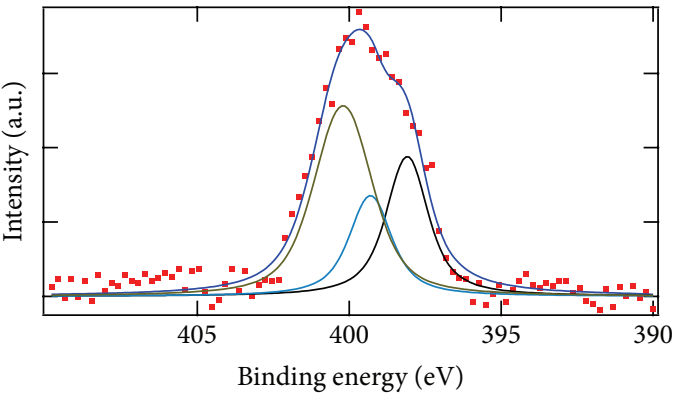

- Raw data

- Fit data

(d)

FIgURE 2: N 1s of 2H-TPP/Fe/Si (100) at (a) RT and (b) $550 \mathrm{~K}$. N 1s of $2 \mathrm{H}-\mathrm{TPP} / \mathrm{Fe}_{3} \mathrm{Si} / \mathrm{Si}$ (100) at (c) RT and (d) $550 \mathrm{~K}$.

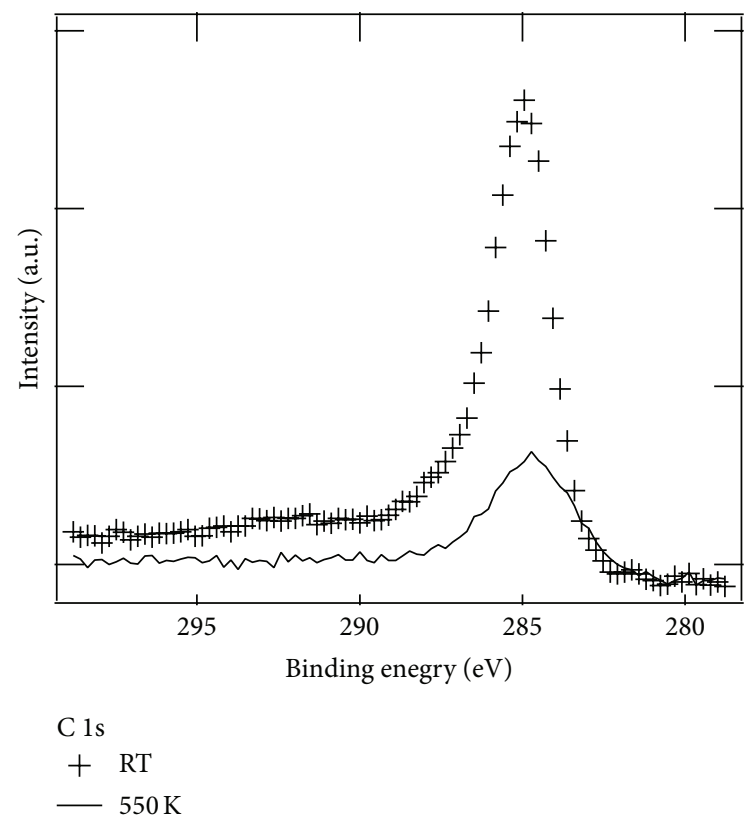

FIGURE 3: C 1s: Core level spectra of 2HTPP on iron and iron-silicide onto Si (100).

shift in BE also measured (shown in Figure by $\Delta_{\mathrm{BE}}=0.99 \mathrm{eV}$ ), which indicate the band formation between Fe and TPP macrocycle.

From calculations, The Fe d states near the Fermi level are expected to have much less hybridization with the $\mathrm{N}$ states,

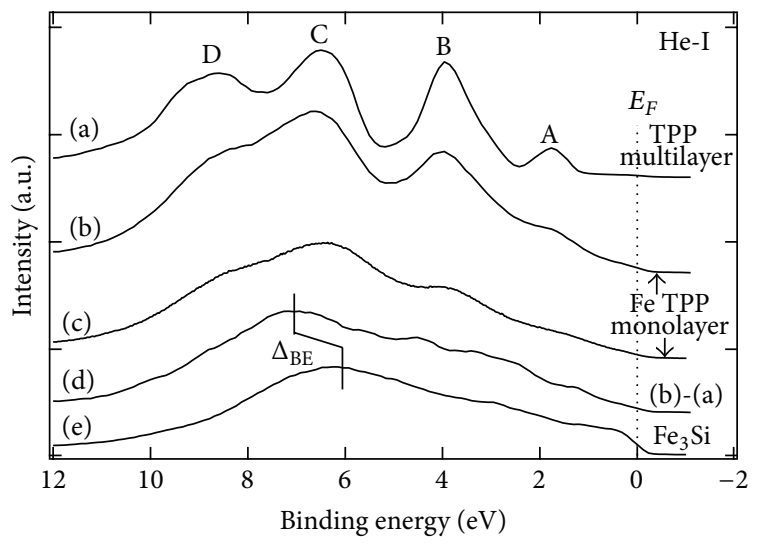

FIGURE 4: Valence band of (a) TPP multilayer on iron or iron silicide onto Si. Monolayer of Fe-TPP on (b) $\mathrm{Fe}_{3} \mathrm{Si}$, (c) Fe onto Si after annealing at $550 \mathrm{~K}$. (d) is difference spectra and (e) $\mathrm{Fe}_{3} \mathrm{Si}$ on $\mathrm{Si}$. The shift $\Delta_{\mathrm{BE}}=0.99 \mathrm{eV}$ is shown here in spectra (d) and (e). Under the experimental spectra, we report the expected contribution of HOMO states and represented by A, B, C, and D respectively.

instead the possible hybridization between the perpendicular $\mathrm{d}$ orbital. The visualization of the valence bands is also important for monitoring the $\mathrm{Fe}$ adatom dosing in molecular layer. The Fe metalation influences the states near the Fermi level, and the Fe d states are expected to hybridize with neighboring $\mathrm{N} p$ states in the energy range $0-5 \mathrm{eV}$ below the Fermi level [33].

To quantitative analysis and understanding the bandbending of the $2 \mathrm{H}-\mathrm{TPP}$ on $\mathrm{Fe}$ onto $\mathrm{Si}$, we illustrated energy 


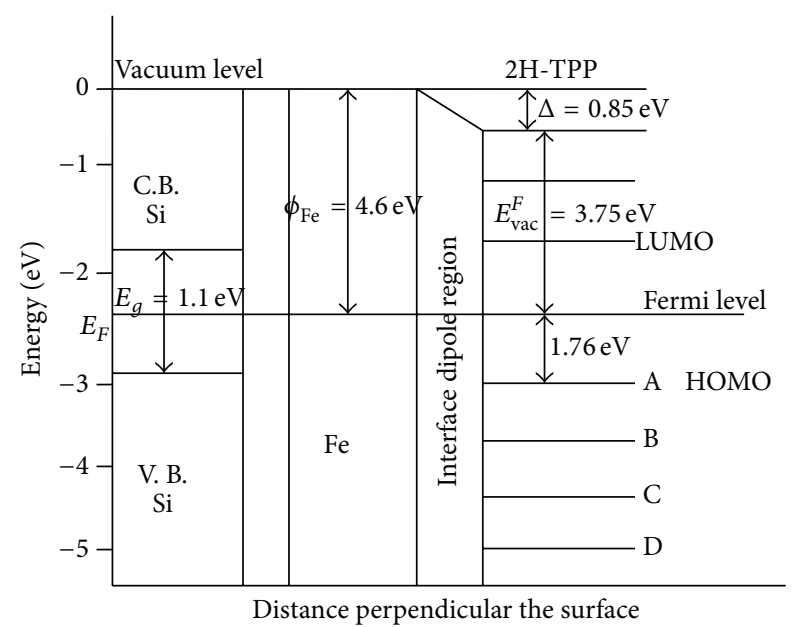

FIgURE 5: Bend-bending diagram of TPP molecules with Fe onto Si. Here, A, B, C, and D represent the HOMO states, respectively, below the Fermi level.

level diagram for this interface and are reported in Figure 5. It is based on porphyrin/metal/Si interfaces [34], in which the energy levels of the porphyrins are fixed to the vacuum level of the metal with a finite energy shift at the interface (calculated shift in work function or vacuum level is $0.85 \mathrm{eV}$ and represented by $\Delta_{\mathrm{VL}}$ ). The vacuum level shifts or adsorbate-induced work function changes (extracted from the widths of the UPS spectra is $0.99 \mathrm{eV}$ ) provide additional information about the nature of the adsorbatesurface interaction and are of potential interest to the organic electronics community [34]. We found work functions of 3.75 and $4.60 \mathrm{eV}$ for monolayer of $2 \mathrm{H}$-TPP and Fe, respectively, compared to $4.95 \mathrm{eV}$ for the clean $\mathrm{Si}(100)$ surface $[35,36]$. The resulting energy-level alignment will affect by various factors. The chemical bonding between the metal and the organic molecule involved a net electronic charge transferred to the metal due to down-shift the vacuum level by introducing a dipole-induced potential step at the interface $[34,37,38]$.

\section{Conlcusion}

The in situ electronic structure of $2 \mathrm{H}$-Tetraphenylporphyrin (2H-TPP) molecules on iron and iron silicide onto Si (100) substrate has been studied by XPS and UPS. The investigations include the formation of $\mathrm{Fe}_{3} \mathrm{Si}$ having $(1 \times 1)$ crystal structure on $\mathrm{Si}$. The 2H-TPP was deposited $\mathrm{Fe}$ and $\mathrm{Fe}_{3} \mathrm{Si}$ onto Si. This reaction needs to be activated by heating the mixed layer at $550 \mathrm{~K}$, indicating a reaction barrier at room temperature. The results revealed that the Fe atom is coordinated by TPP macrocycle on iron $(\mathrm{Fe})$ as well as on iron silicide $\left(\mathrm{Fe}_{3} \mathrm{Si}\right)$ onto $\mathrm{Si}$. XPS results provide the evidence to monitor the progress of the metalation of $2 \mathrm{H}-\mathrm{TPP}$, as the reaction proceed, the two separate peaks of $2 \mathrm{HTPP}$ evolve into a single peak for the metallated porphyrin, because, in the final metalloporphyrin complex, the four nitrogen atoms are chemically equivalent. The fine structure is assigned in the electronic spectra related to HOMO states below the Fermi level. UPS results also support the interaction of the iron and TPP molecules on Si. Finally, the band-bending diagram was drawn upon the reported results. This is particularly important in order to understand orbital interactions, bond formation, and evolution of the electronic properties with doping (oxidation and reduction) in the light of possible applications of porphyrins in donor-acceptor complexes for photovoltaic devices or, given the high molecular symmetry, as prototypical systems for the verification of recent models and phase diagrams for strongly correlated materials [39].

\section{Acknowledgments}

The authors (Chhagan Lal) are thankful for the financial support by ICTP under the "ICTP Program for Training and Research in Italian Laboratories" at Synchrotron, Trieste, Italy, for this work. Chhagan Lal is also grateful to Dr. A. Goldoni at Synchrotron Area Science Park for funding support.

\section{References}

[1] B. C. Stipe, M. A. Rezaei, and W. Ho, "Localization of inelastic tunneling and the determination of atomic-scale structure with chemical specificity," Physical Review Letters, vol. 82, no. 8, pp. 1724-1727, 1999.

[2] C. Santato and F. Rosei, "Organic/metal interfaces: seeing both sides," Nature Chemistry, vol. 2, no. 5, pp. 344-345, 2010.

[3] M. El Garah, F. Palmino, F. Chérioux et al., "Adsorption of zwitterionic assemblies on $\mathrm{Si}(111)-7 \times 7$ : a joint tunneling spectroscopy and ab initio study," Physical Review B, vol. 85, no. 3, Article ID 035425, 2012.

[4] G. P. Loplnski, D. D. M. Wayner, and R. A. Wolkow, "Selfdirected growth of molecular nanostructures on silicon," Nature, vol. 406, no. 6791, pp. 48-51, 2000.

[5] R. J. Hamers, S. K. Coulter, M. D. Ellison et al., "Cycloaddition chemistry of organic molecules with semiconductor surfaces," Accounts of Chemical Research, vol. 33, no. 9, pp. 617-624, 2000.

[6] M. El Garah, Y. Makoudi, F. Palmino et al., "STM and DFT investigations of isolated porphyrin on a silicon-based semiconductor at room temperature," ChemPhysChem, vol. 10, no. 18, pp. 3190-3193, 2009.

[7] J.-C. Lin, J.-H. Kim, J. A. Kellar, M. C. Hersam, S. T. Nguyen, and M. J. Bedzyk, "Building conjugated organic structures on Si(111) surfaces via microwave-assisted sonogashira coupling," Langmuir, vol. 26, no. 6, pp. 3771-3773, 2010.

[8] K. R. Harikumar, J. C. Polanyi, P. A. Sloan, S. Ayissi, and W. A. Hofer, "Electronic switching of single silicon atoms by molecular field effects," Journal of the American Chemical Society, vol. 128, no. 51, pp. 16791-16797, 2006.

[9] K. R. Harikumar, T. Lim, I. R. McNab et al., "Dipole-directed assembly of lines of 1,5-dichloropentane on silicon substrates by displacement of surface charge," Nature Nanotechnology, vol. 3, no. 4, pp. 222-228, 2008.

[10] C. Wçll, Ed., Physical and Chemical Aspects of Organic Electronics, Wiley-VCH, Weinheim, Germany, 2009.

[11] J. L. Hoard, "Some aspects of metalloporphyrin stereochemistry," Annals of the New York Academy of Sciences, vol. 206, pp. 18-31, 1973.

[12] K. M. Kadish, K. M. Smith, and R. Gillard, Eds., The Porphyrin Handbook, Academic Press, San Diego, Calif, USA, 2000. 
[13] P. Vilmercati, C. Castellarin-Cudia, R. Gebauer et al., "Mesoscopic donor-acceptor multilayer by ultrahigh-vacuum codeposition of Zn-tetraphenyl-porphyrin and C70," Journal of the American Chemical Society, vol. 131, no. 2, pp. 644-652, 2009.

[14] E. Baciocchi, O. Lanzalunga, A. Lapi, and L. Manduchi, "Kinetic deuterium isotope effect profiles and substituent effects in the oxidative $\mathrm{N}$-demethylation of N,N-dimethylanilines catalyzed by tetrakis(pentafluorophenyl)porphyrin iron(III) chloride," Journal of the American Chemical Society, vol. 120, no. 23, pp. 5783-5787, 1998.

[15] D. Woehrle, "Porphyrins, phthalocyanines and related systems in polymer phases," Journal of Porphyrins and Phthalocyanines, vol. 4, no. 4, pp. 418-424, 2000.

[16] J. M. Gottfried, K. Flechtner, A. Kretschmann, T. Lukasczyk, and H.-P. Steinrück, "Direct synthesis of a metalloporphyrin complex on a surface," Journal of the American Chemical Society, vol. 128, no. 17, pp. 5644-5645, 2006.

[17] F. Buchner, V. Schwald, K. Comanici, H.-P. Steinrück, and H. Marbach, "Microscopic evidence of the metalation of a freebase porphyrin monolayer with iron," ChemPhysChem, vol. 8, no. 2, pp. 241-243, 2007.

[18] A. Weber-Bargioni, J. Reichert, A. P. Seitsonen, W. Auwärter, A. Schiffrin, and J. V. Barth, "Interaction of cerium atoms with surface-anchored porphyrin molecules," Journal of Physical Chemistry C, vol. 112, no. 10, pp. 3453-3455, 2008.

[19] F. Buchner, K. Flechtner, Y. Bai et al., "Coordination of iron atoms by tetraphenylporphyrin monolayers and multilayers on $\mathrm{Ag}(111)$ and formation of iron-tetraphenylporphyrin," Journal of Physical Chemistry C, vol. 112, no. 39, pp. 15458-15465, 2008.

[20] G. K. Wertheim and P. H. Citrin, "Fermi surface excitations in $\mathrm{X}$-ray photoemission line shapes from metals," in Photoemission in Solids I, vol. 26 of Topics in Applied Physics, pp. 197-236, Springer, New York, NY, USA, 1978.

[21] D. R. Miquita, J. C. González, M. I. N. da Silva et al., "Identification and quantification of iron silicide phases in thin films," Journal of Vacuum Science and Technology A, vol. 26, no. 5, pp. 1138-1148, 2008.

[22] V. Kinsinger, I. Dézsi, P. Steiner, and G. Langouche, "XPS investigations of $\mathrm{FeSi}, \mathrm{FeSi}_{2}$ and $\mathrm{Fe}$ implanted in $\mathrm{Si}$ and $\mathrm{Ge}$," Journal of Physics: Condensed Matter, vol. 2, no. 22, p. 4955, 1990.

[23] B. Egert and G. Panzner, "Bonding state of silicon segregated to $\alpha$-iron surfaces and on iron silicide surfaces studied by electron spectroscopy," Physical Review B, vol. 29, no. 4, pp. 2091-2101, 1984.

[24] M. Pessa, P. Heimann, and H. Neddermeyer, "Photoemission and electronic structure of iron," Physical Review B, vol. 14, no. 8, pp. 3488-3493, 1976.

[25] U. Starke, W. Meier, C. Rath, J. Schardt, W. Weiß, and K. Heinz, "Phase transition and atomic structure of an $\mathrm{Fe}_{3} \mathrm{Si}(100)$ single crystal surface," Surface Science, vol. 377-379, pp. 539-543, 1997.

[26] U. Starke, J. Schardt, W. Weiss et al., "Structural and compositional reversible phase transitions on low-index $\mathrm{Fe}_{3} \mathrm{Si}$ surfaces," Europhysics Letters, vol. 56, no. 6, pp. 822-828, 2001.

[27] D. K. Sarkar, X. J. Zhou, A. Tannous, M. Louie, and K. T. Leung, "Growth of self-assembled copper nanostructure on conducting polymer by electrodeposition," Solid State Communications, vol. 125, no. 7-8, pp. 365-368, 2003.

[28] D. H. Aue, H. M. Webb, and M. T. Bowers, "Photoelectron spectrum and gas-phase basicity of manxine. Evidence for a planar bridgehead nitrogen," Journal of the American Chemical Society, vol. 97, no. 14, pp. 4136-4137, 1975.
[29] Y. Bai, F. Buchner, M. T. Wendahl et al., "Direct metalation of a phthalocyanine monolayer on $\mathrm{Ag}(111)$ with coadsorbed iron atoms," Journal of Physical Chemistry C, vol. 112, no. 15, pp. 60876092, 2008.

[30] J. Xiao, S. Ditze, M. Chen et al., “Temperature-dependent chemical and structural transformations from $2 \mathrm{H}$-tetraphenylporphyrin to copper(II)-tetraphenylporphyrin on $\mathrm{Cu}(111)$," The Journal of Physical Chemistry C, vol. 116, no. 22, pp. 1227512282, 2012.

[31] N. Ueno and S. Kera, "Electron spectroscopy of functional organic thin films: deep insights into valence electronic structure in relation to charge transport property," Progress in Surface Science, vol. 83, pp. 490-557, 2008.

[32] J. Repp, G. Meyer, S. M. Stojkovic, A. Gourdon, and C. Joachim, "Molecules on insulating films: scanning-tunneling microscopy imaging of individual molecular orbitals," Physical Review Letters, vol. 94, no. 2, Article ID 026803, 4 pages, 2005.

[33] P. Panchmata, B. Sanyal, and P. Oppeneer, "GGA + U modeling of structural, electronic, and magnetic properties of iron porphyrin-type molecules," Chemical Physics, vol. 343, no. 1, pp. 47-60, 2008.

[34] H. Ishii, K. Sugiyama, E. Ito, and K. Seki, "Energy level alignment and interfacial electronic structures at organic/metal and organic/organic interfaces," Advanced Materials, vol. 11, no. 8, pp. 605-625, 1999.

[35] J. C. Rivière, Solid State Surface Science, Vol. 1, edited by M. Green, Marcel Dekker, New York, NY, USA, 1969.

[36] G. Hölzl and F. K. Schulte, "Work functions of metals," in Solid Surface Physics, vol. 85-86 of Springer Tracts in Modern Physics, Springer, Berlin, Germany, 1979.

[37] X. Crispin, V. Geskin, A. Crispin et al., "Characterization of the interface dipole at organic/metal interfaces," Journal of the American Chemical Society, vol. 124, no. 27, pp. 8131-8141, 2002.

[38] L. Lindell, M. P. de Jong, W. Osikowicz et al., "Characterization of the interface dipole at the paraphenylenediamine-nickel interface: a joint theoretical and experimental study," Journal of Chemical Physics, vol. 122, no. 8, Article ID 084712, 2005.

[39] M. Capone, M. Fabrizio, C. Castellani, and E. Tosatti, "Strongly correlated superconductivity and pseudogap phase near a multiband mott insulator," Physical Review Letters, vol. 93, no. 4, Article ID 047001, 2004. 

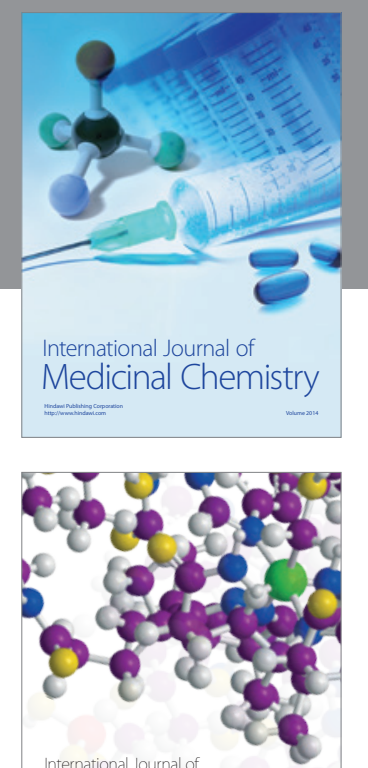

\section{Carbohydrate} Chemistry

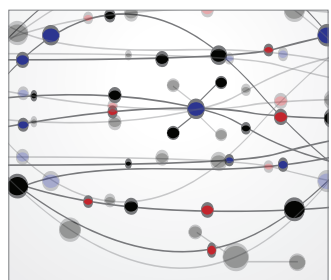

The Scientific World Journal
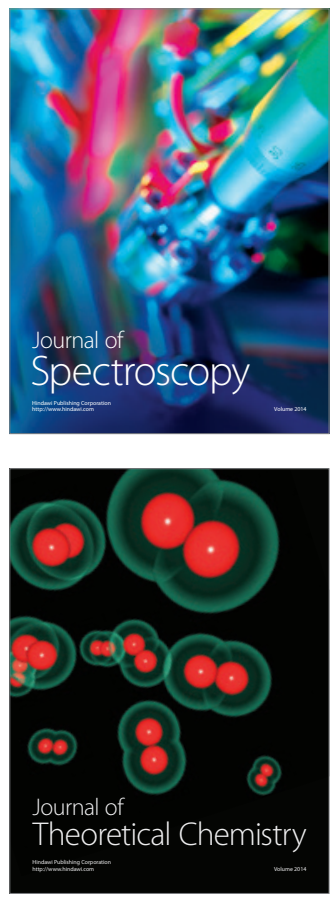
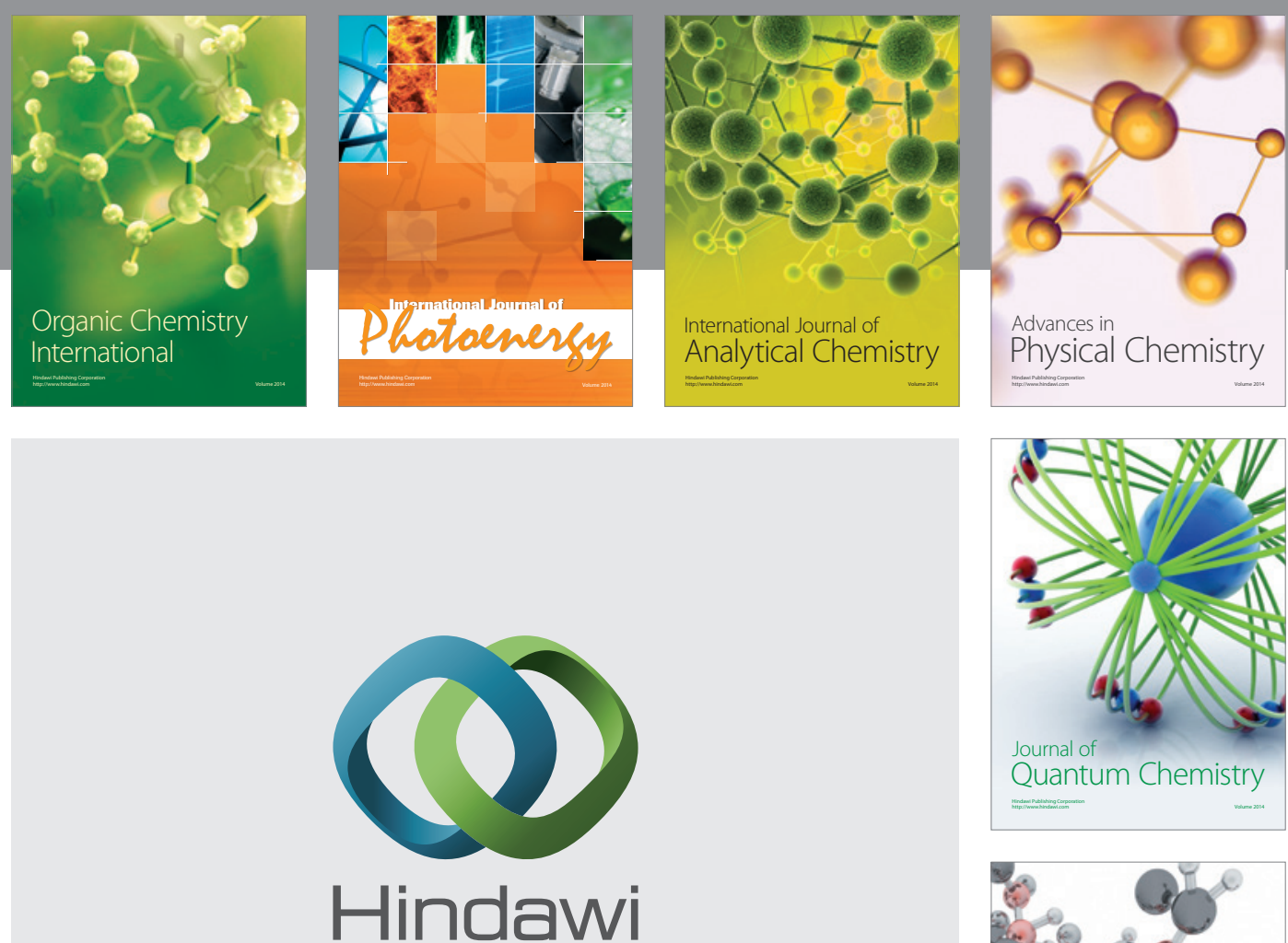

Submit your manuscripts at

http://www.hindawi.com

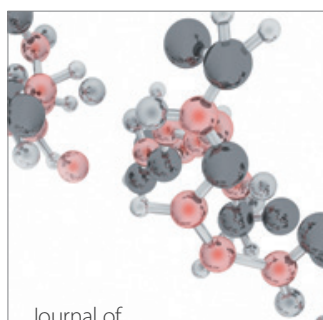

Analytical Methods

in Chemistry

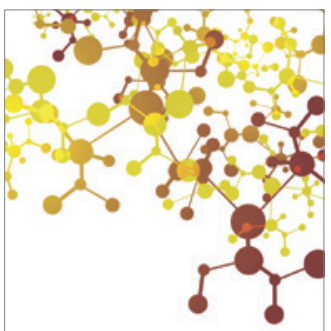

Journal of

Applied Chemistry

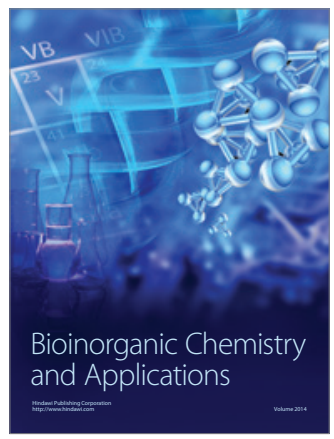

Inorganic Chemistry
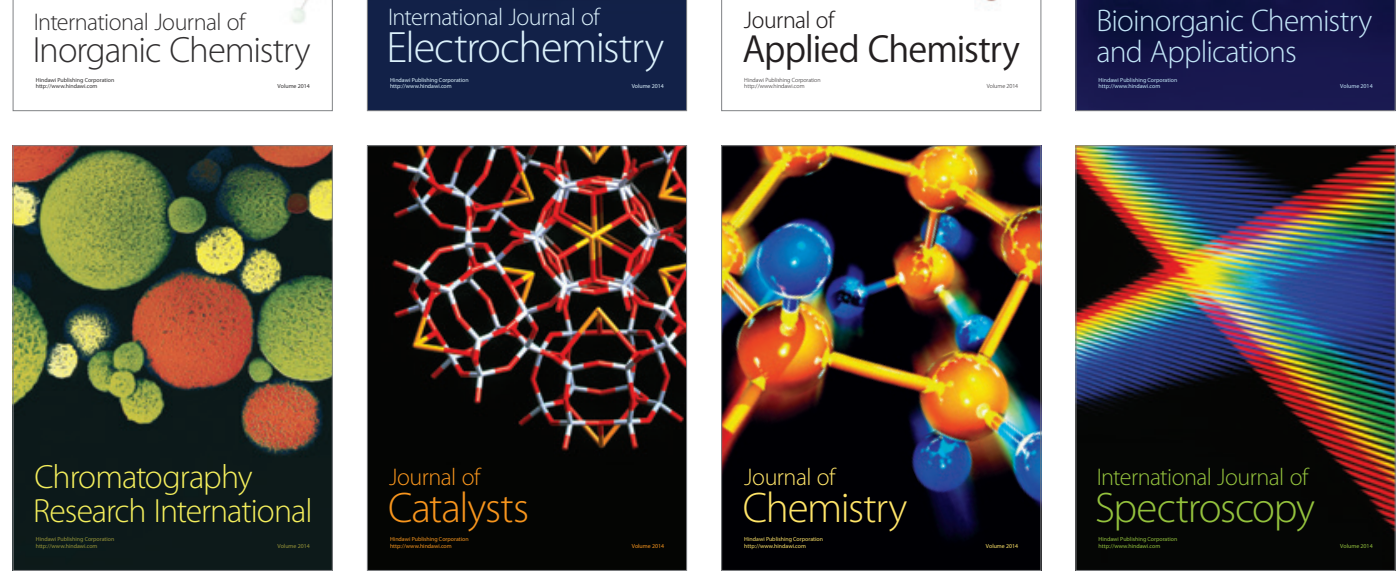